\title{
Multiplex PCR sets of novel microsatellite loci for the great scallop Pecten maximus and their application in parentage assignment
}

\author{
Romain MORVEZEN $^{1}$, Florence CORNETTE ${ }^{2}$, Grégory CHARRIER ${ }^{3}$, Bruno GuINAND $^{4}$, Sylvie LAPÈGUE ${ }^{2}$, \\ Pierre BOUDRY ${ }^{5}$ and Jean LAROCHE ${ }^{1, \mathrm{a}}$ \\ 1 Institut Universitaire Européen de la Mer, Laboratoire des sciences de l'environnement marin, LEMAR, UMR 6539, rue Dumont d'Urville, \\ 29280 Plouzané, France \\ 2 Ifremer, Laboratoire de génétique et pathologie des mollusques marins, 17390 La Tremblade, France \\ 3 Department of Biological and Environmental Sciences - Tjärnö, University of Gothenburg, 45296 Strömstad, Sweden \\ 4 Université de Montpellier II, UMR CNRS 5554, UMR 226, Institut des Sciences de l'Evolution de Montpellier, Place E. Bataillon, cc63, \\ 34095 Montpellier Cedex 5, France \\ 5 Ifremer, Laboratoire des sciences de l'environnement marin, BP 70, 29280 Plouzané, France
}

Received 12 November 2012; Accepted 20 March 2013

\begin{abstract}
We report the isolation, development and multiplex optimisation of 12 new microsatellite loci for the great scallop, Pecten maximus. Diversity was moderate to high, with number of alleles ranging from 4 to 20 and observed heterozygosity between 0.28 and 0.88 . Progeny produced in a commercial hatchery was used to test locus power for parentage assignment. The percentage of offspring that was unambiguously assigned to a unique pair of parents was 97\% (software package CERVUS-COLONY). Parentage assignment revealed that $22 \%$ of the studied progeny resulted from unplanned crosses. Effective population size of the study progeny was also estimated. Our study illustrates the power of microsatellites for the genetic monitoring of hatchery-produced great scallops.
\end{abstract}

Keywords: Microsatellites / Polymerase chain reaction / Parentage / Assignment / Bivalve mollusc

\section{Introduction}

The great scallop Pecten maximus (L.) is an economically important bivalve in Europe, mainly in France and the United Kingdom (FAO Fisheries Department, 2000). Production is based on dredge fishing of wild populations or sea-ranched stocks produced in hatcheries. The demographic consequences of hatchery-based population enhancement and potential genetic impact remain mostly unexplored (Beaumont and Gjedrem 2006). Previous genetic studies have been conducted on $P$. maximus, using either allozymes or mitochondrial DNA (Beaumont et al. 1993; Rigaa et al. 1997; Wilding et al. 1998; Saavedra and Pena 2005). However, because of the low diversity and/or pattern of inheritance, these markers allow only poor tracking, if any, of the impact of hatchery stocks on wild populations.

As codominant, highly variable, biparentally inherited markers, microsatellites are widely used in a variety of fundamental and applied sciences. They are especially useful for the characterization of genetic stocks, parentage analysis and broodstock selection, linkage mapping, and studies of

\footnotetext{
${ }^{a}$ Corresponding author: jean.laroche@univ-brest.fr
}

quantitative trait loci (Chistiakov et al. 2006). However, few microsatellite markers have been described so far for $P$. $\max$ imus (Watts et al. 2005; Charrier et al. 2012).

With the development of next-generation sequencing technologies, microsatellite loci are becoming more readily available, even for non-model species (Guichoux et al. 2011). Multiplex sets of microsatellites are more efficient and reduce manual error (Porta et al. 2006; Guichoux et al. 2011). Microsatellites have been proven to be a valuable tool in parentage studies of bivalves (Taris et al. 2007; Li et al. 2010; Sekino et al. 2010; Wang et al. 2010). In the present paper, we report the development of novel microsatellite markers for the great scallop, their optimization in multiplex PCRs and their application in parentage assignment using progeny produced in a commercial hatchery.

\section{Materials and methods}

\subsection{Biological material and DNA extraction}

Forty-eight individuals were sampled by dredging in the Bay of Brest (Finistère, France). In addition, a cohort produced 
in 2011 in Le Tinduff commercial hatchery (Plougastel, France) was studied by sampling the 26 genitors according to a crossing scheme provided by the hatchery. The great scallop is a simultaneous hermaphrodite, so individuals produce both female and male gametes. However, scallops do not release male and female products at the same time, allowing for separation between spawning events. Gamete separation was performed to minimize self-fertilization, as this a major concern for hatchery production. In the studied cohort, gametes from each of the individuals used as female were fertilized by 3-4 males. Overall, 24 crosses were performed with 11 individuals used only as females, 13 used both as females and as males, and 2 used only as males. From this progeny, 162 offspring were sampled when 9 months old. For all individuals, a fragment of the adductor muscle was individually collected and preserved in $85 \%$ ethanol. Subsequently, DNA extraction was performed using the QIAamp DNA Mini Kit (Qiagen $^{\mathrm{TM}}$, Hilden, Germany) according to the manufacturer's instructions.

\subsection{Microsatellite identification and primer design}

Microsatellite sequences were identified with the 454 GS-FLX Titanium pyrosequencing method, as described by Malausa et al. (2011). Pyrosequencing was performed by Genoscreen (Lille, France). Original sequences produced by pyrosequencing were trimmed using the QDD pipeline designed by Meglecz et al. (2010) ${ }^{1}$. A database of 2260 microsatellite loci with a number of repeats $\geqslant 5$ was obtained. Primers for PCR amplification were automatically designed by the QDD pipeline using the software's default parameters (Meglecz et al. 2010). Forty-five microsatellite sequences were chosen for further testing, based on melting temperature of the designed primers, theoretical amplified fragment size and microsatellite motif. Additionally, each forward primer was tailed with a universal primer to reduce genotyping cost. Four different tails (from Schuelke 2000) were used, corresponding to four different fluorescent dyes: FAM-TGTAAAACGACGCCCAGT, DO-TAGAAGGCACAGTCGAGG, YY-GCCGCTCTAGAACTAGTG and PET-GCAGGAAACAGCTATGAC (Table 1).

\subsection{Simplex development}

PCR amplifications were first tested on seven individuals and a negative control $\left(\mathrm{H}_{2} \mathrm{O}\right)$ in simplex condition, in a $15 \mu \mathrm{L}$ reaction volume composed of $0.067 \mathrm{U}$ Diamond Taq ${ }^{\circledR}$ DNA polymerase (Eurogentec, Seraing, Belgium), $1 \times$ Reaction Buffer (Eurogentec), $2 \mathrm{mM} \mathrm{MgCl}_{2}, 0.08 \mathrm{mM}$ dNTPs, $0.8 \mu \mathrm{M}$ of forward primer, $0.4 \mu \mathrm{M}$ reverse primer and $10 \mathrm{ng}$ genomic DNA. A touchdown PCR was performed with the following thermocycling regime: $96{ }^{\circ} \mathrm{C}$ for $5 \mathrm{~min}, T_{\mathrm{a}}$ for $2 \mathrm{~min}$, $72{ }^{\circ} \mathrm{C}$ for $45 \mathrm{~s},\left(96{ }^{\circ} \mathrm{C} 30 \mathrm{~s}, T_{\mathrm{a}}-1{ }^{\circ} \mathrm{C} 45 \mathrm{~s}\left[-1{ }^{\circ} \mathrm{C}\right.\right.$ per cycle until $\left.55{ }^{\circ} \mathrm{C}\right], 72{ }^{\circ} \mathrm{C}$ for $\left.45 \mathrm{~s}\right) \times 4-6$ cycles and $\left(96^{\circ} \mathrm{C} 30 \mathrm{~s}, 55^{\circ} \mathrm{C}\right.$ for $45 \mathrm{~s}, 72{ }^{\circ} \mathrm{C}$ for $\left.45 \mathrm{~s}\right) \times 23-25$ cycles, $72{ }^{\circ} \mathrm{C}$ for $15 \mathrm{~min}$. Amplification success was checked by running PCR products

${ }^{1}$ QDD is freely available under the GPL licence for Windows and Linux from the following web site: http://www.univ-provence. fr/gsite/Local/egee/dir/meglecz/QDD.html on an agarose gel (1.5\% agarose, $1 \mathrm{X}$ TAE) for $45-60 \mathrm{~min}$ at $100 \mathrm{~V}$.

Loci that were successfully amplified were then tested with a forward tailed primer, using a modified protocol from Lallias et al. (2009). PCR amplifications were conducted in a $15 \mu \mathrm{l} \mathrm{re-}$ action volume composed of: 0.0167 U Diamond Taq ${ }^{\circledR}$ DNA polymerase (Eurogentec), 1× Reaction Buffer (Eurogentec), $2 \mathrm{mM} \mathrm{MgCl}_{2}, 0.08 \mathrm{mM}$ of dNTPs, $0.04 \mu \mathrm{M}$ tailed forward primer, $0.267 \mu \mathrm{M}$ reverse primer, $0.267 \mu \mathrm{M}$ universal primer and $10 \mathrm{ng}$ genomic DNA. PCR amplifications were performed with (1) an initial cycle: $96{ }^{\circ} \mathrm{C}$ for $5 \mathrm{~min}, T_{\mathrm{a}}$ for $2 \mathrm{~min}, 72{ }^{\circ} \mathrm{C}$ for $2 \mathrm{~min},\left(96{ }^{\circ} \mathrm{C} 30 \mathrm{~s}, T_{\mathrm{a}} 45 \mathrm{~s}, 72{ }^{\circ} \mathrm{C} 45 \mathrm{~s}\right) \times 29$ cycles, followed by (2) a "nested" PCR step to optimize amplification with the universal primer: $\left(96{ }^{\circ} \mathrm{C} 30 \mathrm{~s}, 55^{\circ} \mathrm{C} 45 \mathrm{~s}\right.$ and $72{ }^{\circ} \mathrm{C}$ $45 \mathrm{~s}) \times 8$ cycles, $72{ }^{\circ} \mathrm{C}$ for $15 \mathrm{~min}$.

PCR products were mixed with formamide and GeneScan 500-LIZ size standard (Applied Biosystems ${ }^{\mathrm{TM}}$ Carlsbad, CA, USA) $[1 \mu \mathrm{l}$ PCR product, $10 \mu \mathrm{l}$ Hi-Di Formamide (Applied Biosystems $^{\mathrm{TM}}$ ), $0.15 \mu \mathrm{l}$ GS500-LIZ]. After five minutes of denaturation $\left(96^{\circ} \mathrm{C}\right)$ and a rapid cooling on ice, PCR products were electrophoresed on a capillary sequencer (ABI-3130xl, Applied Biosystem ${ }^{\mathrm{TM}}$ ). Fragment lengths were assessed with the GeneMapper ${ }^{\circledR} 4.0$ software (Life Technologies ${ }^{\mathrm{TM}}$ ). The loci that provided clear signals were genotyped on the 48 wild individuals.

\subsection{Statistical analysis for microsatellite development}

Numbers of alleles $\left(N_{\mathrm{a}}\right)$ and observed $\left(H_{\mathrm{obs}}\right)$ heterozygosity were calculated for each locus using CERVUS 3.0 (Kalinowski et al. 2007). Departure from Hardy-Weinberg equilibrium was estimated by calculating $F_{\text {IS }}$ values according to Weir and Cockerham (1984) with GENETIX v4.05 (www.genetix.univ-montp2.fr), and their statistical significance was tested with 10000 permutations. Linkage disequilibrium was tested with GENEPOP 4.0 (Rousset 2008) using the Markov chain method (10000 dememorisation steps, 100 batches, 5000 iterations) and Fisher's exact test; a Bonferroni correction for multiple testing was applied. Null allele frequency estimates were computed using CERVUS 3.0. The eight best quality loci were selected for the multiplexing process, in addition to three loci from the literature: LIST-15_005 and LIST-15_012 (Watts et al. 2005) and PmGC05 (Charrier et al. 2012).

\subsection{Optimization of multiplex PCRs}

To optimize the genotyping accuracy, selected loci were organized into three multiplex sets that minimized overlapping allelic ranges. PCR amplifications were conducted with the Type-it Microsatellite PCR Kit (Qiagen ${ }^{\mathrm{TM}}$ ) in a $10 \mu$ l reaction volume containing $5 \mu \mathrm{l}$ of Type-it Multiplex PCR Master Mix (2X) (including HotStarTaq ${ }^{\circledR}$ Plus DNA Polymerase, Type-it Microsatellite PCR Buffer with $6 \mathrm{mM} \mathrm{MgCl}_{2}$, and dNTPs), $1 \mu \mathrm{l}$ primer mix (see Table 2 for details), $1 \mu \mathrm{l}$ Q-solution $(5 \times)$ $2 \mu \mathrm{l}$ RNase-free water and $1 \mu \mathrm{l}$ genomic DNA (10 ng). PCRs included an initial step: $95{ }^{\circ} \mathrm{C}$ for $15 \mathrm{~min}\left(94{ }^{\circ} \mathrm{C} 30 \mathrm{~s}, 59{ }^{\circ} \mathrm{C}\right.$ $90 \mathrm{~s}$ and $\left.72^{\circ} \mathrm{C} 90 \mathrm{~s}\right) \times 30$ cycles, followed by a "nested" PCR step $\left(94{ }^{\circ} \mathrm{C} 30 \mathrm{~s}, 55^{\circ} \mathrm{C} 90 \mathrm{~s}\right.$ and $\left.72{ }^{\circ} \mathrm{C} 90 \mathrm{~s}\right) \times 8$ cycles, 


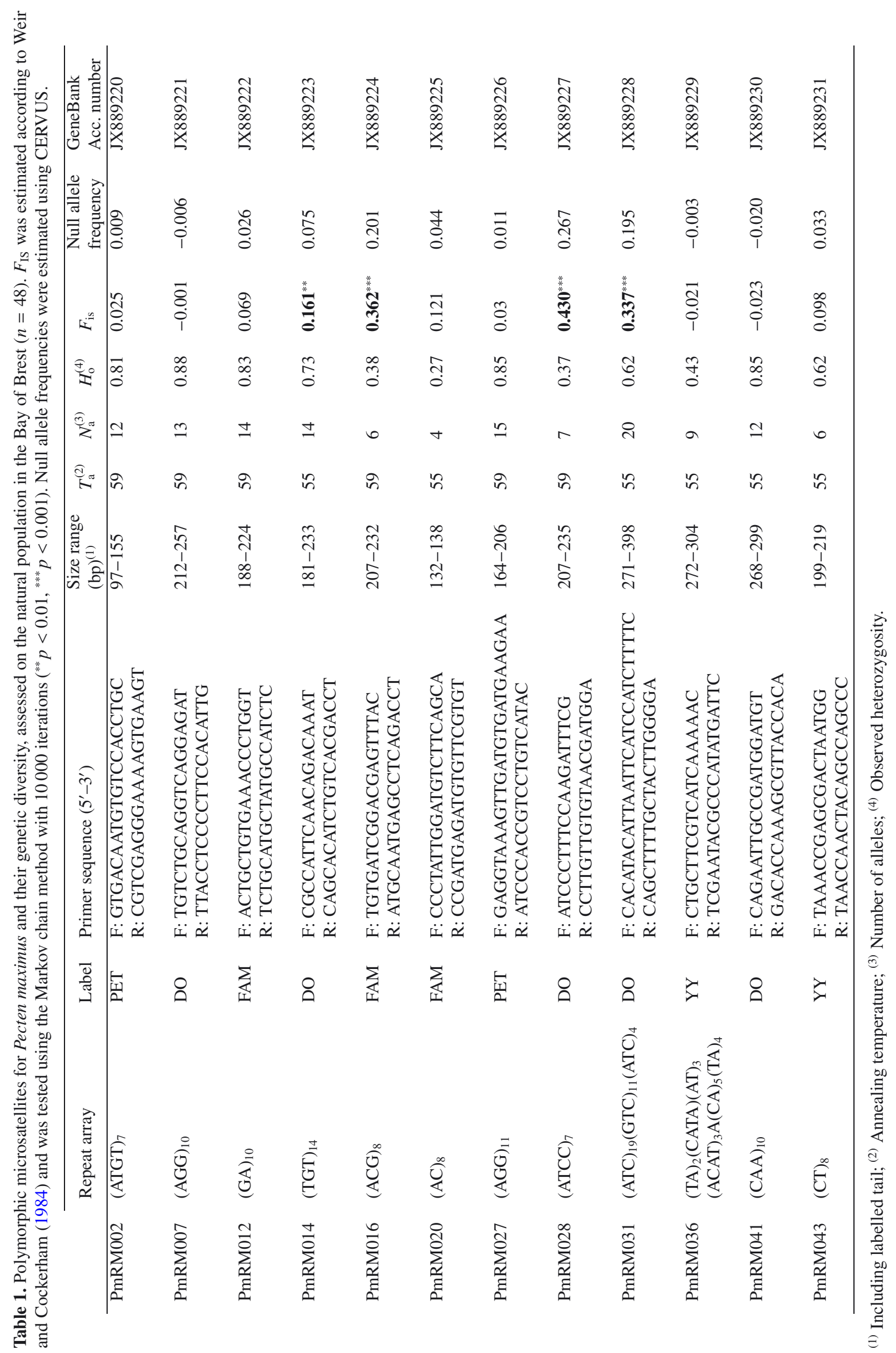


Table 2. Characteristics of the three microsatellite PCR multiplexes in Pecten maximus, and associated statistics assessed on the aquaculture production.

\begin{tabular}{|c|c|c|c|c|c|c|c|}
\hline & $\begin{array}{c}\text { Conc. }(\mu \mathrm{M}) \\
\text { F, } \mathrm{R} \text { and } \mathrm{M} 13\end{array}$ & Size range ${ }^{(1)}(b p)$ & $N_{\mathrm{a}}^{(2)}$ & $\mathrm{PIC}^{(3)}$ & $\mathrm{NE}-1 \mathrm{P}^{(4)}$ & $\mathrm{NE}-2 \mathrm{P}^{(5)}$ & NE-PP(6) \\
\hline \multicolumn{8}{|c|}{ PCR multiplex set 1} \\
\hline & 0.010 & & & & & & \\
\hline \multirow{3}{*}{ PmRM020 } & 0.050 & $132-138$ & 3 & 0.111 & 0.993 & 0.942 & 0.892 \\
\hline & 0.042 & & & & & & \\
\hline & 0.030 & & & & & & \\
\hline \multirow[t]{3}{*}{ PmRM036 } & 0.150 & $272-304$ & 5 & 0.252 & 0.964 & 0.858 & 0.747 \\
\hline & 0.125 & & & & & & \\
\hline & 0.030 & & & & & & \\
\hline \multirow[t]{3}{*}{ PmRM007 } & 0.150 & $212-257$ & 13 & 0.872 & 0.383 & 0.235 & 0.086 \\
\hline & 0.125 & & & & & & \\
\hline & 0.010 & & & & & & \\
\hline \multirow[t]{2}{*}{ PmRM027 } & 0.050 & $164-206$ & 12 & 0.813 & 0.497 & 0.327 & 0.151 \\
\hline & 0.042 & & & & & & \\
\hline \multicolumn{8}{|c|}{ PCR multiplex set 2} \\
\hline \multirow{4}{*}{ PmRM012 } & 0.020 & & & & & & \\
\hline & 0.100 & $188-224$ & 16 & 0.895 & 0.326 & 0.194 & 0.06 \\
\hline & 0.083 & & & & & & \\
\hline & 0.030 & & & & & & \\
\hline \multirow[t]{3}{*}{ PmRM043 } & 0.150 & 199-219 & 10 & 0.639 & 0.721 & 0.538 & 0.333 \\
\hline & 0.125 & & & & & & \\
\hline & 0.030 & & & & & & \\
\hline \multirow[t]{3}{*}{ PmRM041 } & 0.150 & $268-299$ & 11 & 0.804 & 0.513 & 0.341 & 0.162 \\
\hline & 0.125 & & & & & & \\
\hline & 0.010 & & & & & & \\
\hline \multirow[t]{2}{*}{ PmRM002 } & 0.050 & $97-155$ & 12 & 0.835 & 0.457 & 0.294 & 0.126 \\
\hline & 0.042 & & & & & & \\
\hline \multicolumn{8}{|c|}{ PCR multiplex set 3} \\
\hline \multirow{4}{*}{ PmGC05 } & 0.090 & & & & & & \\
\hline & 0.450 & $176-194$ & 9 & 0.701 & 0.655 & 0.478 & 0.288 \\
\hline & 0.375 & & & & & & \\
\hline & 0.030 & & & & & & \\
\hline \multirow{3}{*}{ LIST15-005 } & 0.150 & $263-303$ & 12 & 0.866 & 0.398 & 0.247 & 0.094 \\
\hline & 0.125 & & & & & & \\
\hline & 0.030 & & & & & & \\
\hline \multirow[t]{2}{*}{ LIST15-012 } & 0.150 & $199-223$ & 9 & 0.777 & 0.562 & 0.385 & 0.206 \\
\hline & 0.125 & & & & & & \\
\hline
\end{tabular}

(1) Including labelled tail; (2) number of alleles; (3) polymorphic information content; (4) non-exclusion probability for one candidate parent; (5) non-exclusion probability for one candidate parent given the genotype of a known parent of the opposite sex; ${ }^{(6)}$ non-exclusion probability for a candidate parent pair.

and $60{ }^{\circ} \mathrm{C}$ for $10 \mathrm{~min}$. PCR products were then analyzed as described above for simplex amplifications. Samples from Le Tinduff hatchery (26 parents and 162 progenies) were genotyped using the optimized multiplex sets, in order to test the power of these markers for parentage assignment.

\subsection{Parentage assignment}

In order to estimate theoretical power of the microsatellites with a varying number of genitors, simulations of parentage assignment were conducted using the likelihood-based approach in CERVUS 3.0, with the following parameters: 10000 replication cycles, 10 to 200 candidate parents, $100 \%$ of candidate parents sampled, $95 \%$ loci typed and a $1 \%$ error rate. Two analyses were performed on the hatchery-produced progeny.
First, parentage assignment was conducted based on the likelihood approach as implemented in CERVUS 3.0. Second, a sibship reconstruction of the offspring was performed with COLONY 2.0 (Jones and Wang 2010), without including the parents. If similar results were given by both methods (i.e., if siblings found by COLONY with error rate $1 \%$ were congruent with those detected from the assignment with CERVUS, also for error rate $1 \%$ ), the assignment was validated.

\subsection{Estimation of effective population size}

Effective population size was estimated by two methods. First, the method based on sibship assignment (SA) (Wang 2009), implemented in COLONY. Second, the method based on linkage disequilibrium (LD), implemented in LDNe 


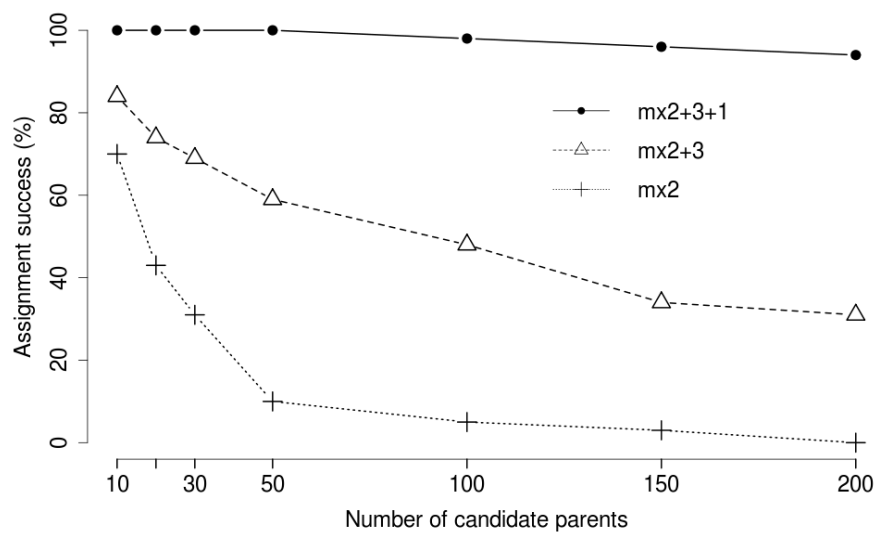

Fig. 1. Assignment success rate of simulated genotype data at the 99\% confidence level. Each multiplex was added in decreasing order of polymorphic information content (PIC).

(Waples and Do 2010). For this method, $P_{\text {crit }}$ was set at 0.02 , as recommended by the authors.

\section{Results}

\subsection{Microsatellite variability}

Of the 45 primer pairs tested, 21 (46.6\%) produced clear and unique bands following electrophoresis on agarose gels. Among these, 13 showed a fluorescent signal without PCR artifacts on the capillary sequencer. Only one locus was found monomorphic on the seven tested individuals. The 12 remaining loci (Table 1) were then genotyped on 48 individuals. Statistics for each locus are given in Table 1. Overall polymorphism was moderate to high, with $N_{\mathrm{a}}$ varying from 4 to 20 alleles, and $H_{\mathrm{o}}$ from 0.28 to 0.88 (with $H_{\mathrm{o}}>0.8$ for 5 loci).

Significant departure from Hardy-Weinberg equilibrium (i.e., significant $F_{\text {is }}$ ) was found in four markers. The same markers displayed null allele frequency estimates superior to 0.05 . These loci were discarded before multiplex optimization. No significant linkage disequilibrium was detected among markers. Three multiplex PCR were developed, with reliable amplification signals at $T_{\mathrm{a}}=59{ }^{\circ} \mathrm{C}$, despite the different $T_{\mathrm{a}}$ in simplex PCR (Table 2). Overlapping of allele size ranges within a multiplex could not be avoided in one case (multiplex set 2: PmRM012 and PmRM043).

\subsection{Parentage assignment power}

Genetic diversity and exclusion probabilities in the studied progeny are shown in Table 2. The combined exclusion power was greater than $99.99 \%$ across the three sets. The results of the CERVUS simulations (Fig. 1) showed that the three multiplexes are required to reach $100 \%$ assignment, even with a relatively small number $(<50)$ of candidate parents. Moreover, even with all three multiplexes, $100 \%$ assignment was not reached if the number of candidate parents was higher than 50 individuals (98\% for 100 parents, $94 \%$ for 200 parents).

To further test the potential of the present set of multiplexed markers, parentage assignment in the hatchery produced progeny was conducted on 162 offspring sampled within a cohort known to result from crossings using a total of 26 parents. Among these offspring, 13 individuals were excluded due to a lack of amplification for more than $30 \%$ of loci, most likely caused by poor quality DNA. In the 149 remaining individuals, 144 (96\%) were assigned to a parental pair with a confidence level $>99 \%$. This corresponded to 29 fullsib families with a number of siblings varying from 2 to 16 per family, and 20 families composed of a single offspring. Additionally, 23 half-sib families were found. The sibling reconstruction conducted with COLONY, correctly reconstructed all sibling pairs found with CERVUS, except for three pairs (congruence rate: $98 \%$ ). The combined results of the two analyses performed with CERVUS and COLONY are given in Figure 2.

Twenty-three genitors out of twenty-six had at least one offspring in the dataset, but the reproductive contributions were very uneven. The number of offspring per genitor varied from 1 to 41 . Two genitors in particular appeared more successful than the others, with a contribution to the progeny of 29\% for PmG073 (used both as female and male) and 26\% for PmG074 (used only as a female).

Results found with parentage assignment were compared to the crossing plan that had been performed by Le Tinduff hatchery. Offspring from only $33 \%$ of crossings done in the hatchery were found in the data set. Among all juveniles analyzed, 113 (79\%) were coherent with the crossing plan, but 31 appeared to be progenies of unintentionally crossed genitors.

Effective population size was estimated at $\mathrm{Ne}=33 \mathrm{CI}$ 95\%, 31-69) by the SA method, and $\mathrm{Ne}=24.3$ (CI 95\%, 22.4-26.3) by the LD method.

\section{Discussion}

The new microsatellites display the same range of variability as those described previously in $P$. maximus by Watts et al. (2005), which were also isolated from genomic DNA. In contrast, the present markers are more polymorphic than those identified by Charrier et al. (2012) that were derived from expressed sequence tags (Na varying from 2 to 11 alleles, and $H_{\mathrm{o}}$ from 0.05 to 0.84 ). Loci where null alleles were found were not kept (Table 1), as they can induce significant bias in parentage analysis (Jones et al. 2010).

As highlighted in Figure 1, all three multiplexes are required to reach $100 \%$ assignment. This result is slightly different than those obtained from previous studies on marine bivalves (Li et al. 2010; Nie et al. 2012), which find that a smaller number of multiplexes was required. The slightly lower polymorphic information content (PIC) and number of markers in our study are most likely the cause of this difference.

The low number of crossing done in the hatchery with at least one offspring present in the data set indicates either strong larval mortalities or high differential in reproduction success among genitors. Such observations seem common in hatcheryreared bivalves, as notably reported by Boudry et al. (2002) and Lallias et al. (2010).

The high number of offspring produced by unintentionally crossed genitors could be explained by technical constraints in the hatchery. Contamination by male and/or female gametes and subsequent uncontrolled fertilization might have led to production of progenies with unexpected parental pairs. In the future, a better monitoring of the hatchery production should lead to a reduction of these unexpected crossings. 


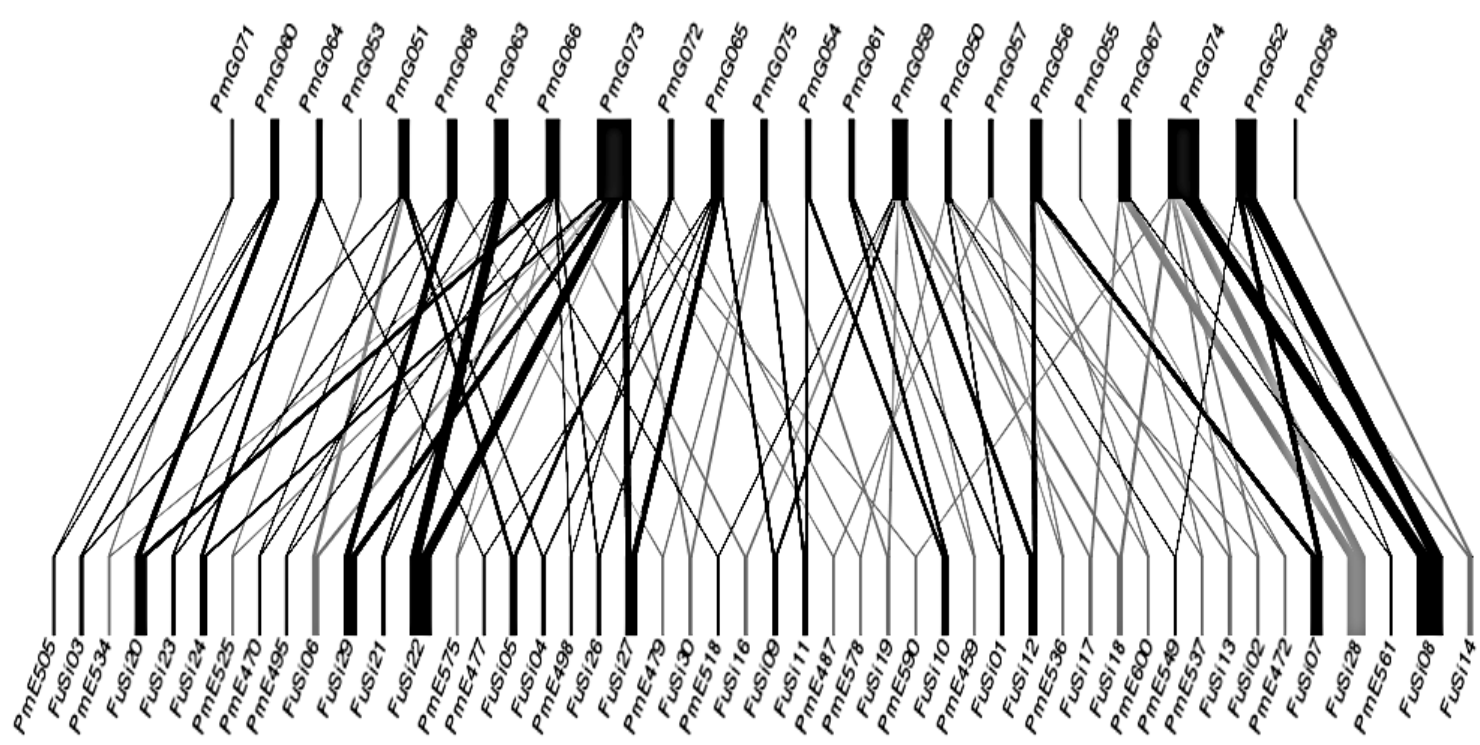

Fig. 2. Parentage assignment (as found by likelihood-method implemented in CERVUS v. 3.0) and sibling reconstruction (as found by COLONY) in the hatchery progeny. Upper boxes: genitors (size proportional to the number of offspring). Lower boxes: offspring, grouped by full-sib family (size proportional to family size; grey: offspring from unplanned parental pair; black: offspring from planned parental pair).

Both estimates of effective population size are in the order of magnitude expected with the number of breeders used by the hatchery (26), and thus both methods appear accurate. The small difference between estimates can be explained by the differences in prior assumptions made by the methods. The sibship assignment method is relatively unaffected by nonrandom mating (as is the case here), whereas the linkage disequilibrium method requires it (Wang 2009).

This study highlights the power of microsatellites to monitor genetic diversity in great scallop hatcheries and to estimate effective population sizes. By assessing the contribution of each genitor to the hatchery progenies, genetic tools give the possibility to monitor effective breeding size (e.g., see Boudry et al. 2002; Lallias et al. 2010), which is an important parameter for the maintenance of genetic diversity in commercial hatcheries. In addition, genetic monitoring can be used to track undesired crossings, which would be particularly valuable in future selective breeding programs.

Acknowledgements. We would like to thank the staff of Le Tinduff hatchery for their lasting and ongoing cooperation with our laboratory, especially J.-P. Carval, M.L. Muzellec and F. Breton. We also thank S. Heurtebise, E. Lavergne and I. Calves for their technical assistance. This research was funded through the European project REPROSEED (KBBE-3-245119).

\section{References}

Beaumont A., Gjedrem T., 2006, Scallops - Pecten maximus and P. jacobaeus. In: Crosetti D., Lapègue S., Olesen I., Svasaand T. (Eds.). Genetic effects of domestication, culture and breeding of fish and shellfish, and their impacts on wild population. GENIMPACT project: Evaluation of genetic impact of aquaculture activities on native populations: a European network. Workshop, Viterbo, Italy, 12-17th June, 2006, pp. 62-69, http:// genimpact.imr.no/
Beaumont A.R., Morvan C., Huelvan S., Lucas A., Ansell A.D., 1993, Genetics of indigenous and transplanted population of Pecten maximus - no evidence for the existence of separate stocks. J. Exp. Mar. Biol. Ecol. 169, 77-88.

Boudry P., Collet B., Cornette F., Hervouet V., Bonhomme F., 2002, High variance in reproductive success of the Pacific oyster (Crassostrea gigas Thunberg) revealed by microsatellite-based parentage analysis of multifactorial crosses. Aquaculture 204, 283-296.

Charrier G., Morvezen R., Calves I., Laroche J., 2012, Development of new microsatellite markers derived from expressed sequence tags for the great scallop (Pecten maximus). Conserv. Genet. Resour. 4, 931-934.

Chistiakov D.A., Hellemans B., Volckaert F.A.M., 2006, Microsatellites and their genomic distribution, evolution, function and applications: A review with special reference to fish genetics. Aquaculture 255, 1-29.

FAO Fisheries Department, Data and Statistics Unit, 2000, FISHSTAT Plus: Universal software for fishery statistical time series.

Guichoux E., Lagache L., Wagner S., Chaumeil P., Leger P., Lepais O., Lepoittevin C., Malausa T., Revardel E., Salin F., Petit R.J., 2011, Current trends in microsatellite genotyping. Mol. Ecol. Resour. 11, 591-611.

Jones A.G., Small C.M., Paczolt K.A., Ratterman N.L., 2010, A practical guide to methods of parentage analysis. Mol. Ecol. Resour. $10,6-30$.

Jones O.R., Wang J.L., 2010, COLONY: a program for parentage and sibship inference from multilocus genotype data. Mol. Ecol. Resour. 10, 551-555.

Kalinowski S.T., Taper M.L., Marshall T.C., 2007, Revising how the computer program CERVUS accommodates genotyping error increases success in paternity assignment. Mol. Ecol. 16, 10991106.

Lallias D., Stockdale R., Boudry P., Beaumont A.R., Lapegue S., 2009, Characterization of 27 microsatellite loci in the European flat oyster Ostrea edulis. Mol. Ecol. Resour. 9, 960-963. 
Lallias D., Taris N., Boudry P., Bonhomme F., Lapegue S., 2010, Variance in the reproductive success of flat oyster Ostrea edulis L. assessed by parentage analyses in natural and experimental conditions. Genet. Res. 92, 175-187.

Li R., Li Q., Cornette F., Degremont L., Lapegue S., 2010, Development of four EST-SSR multiplex PCRs in the Pacific oyster (Crassostrea gigas) and their validation in parentage assignment. Aquaculture 310, 234-239.

Malausa T., Gilles A., Meglecz E., Blanquart H., Duthoy S., Costedoat C., Dubut V., Pech N., Castagnone-Sereno P., Delye C., Feau N., Frey P., Gauthier P.., Guillemaud T., Hazard L., Le Corre V., Lung-Escarmant B., Male P.J.G., Ferreira S., Martin J.F., 2011, High-throughput microsatellite isolation through 454 GS-FLX Titanium pyrosequencing of enriched DNA libraries. Mol. Ecol. Resour. 11, 638-644.

Meglecz E., Costedoat C., Dubut V., Gilles A., Malausa T., Pech N., Martin J.F., 2010, QDD: a user-friendly program to select microsatellite markers and design primers from large sequencing projects. Bioinformatics 26, 403-404.

Nie H.T., Li Q., Kong L.F., 2012, Development of four multiplex PCRs in the zhikong scallop (Chlamys farreri) and their validation in parentage assignment. Biochem. Syst. Ecol. 44, 96-101.

Porta J., Porta J.M., Martinez-Rodriguez G., Alvarez M.D., 2006, Development of a microsatellite multiplex PCR for Senegalese sole (Solea senegalensis) and its application to broodstock management. Aquaculture 256, 159-166.

Rigaa A., Cellos D., Monnerot M., 1997, Mitochondrial DNA from the scallop Pecten maximus: An unusual polymorphism detected by restriction fragment length polymorphism analysis. Heredity 79, 380-387.

Rousset F., 2008, GENEPOP' 007: a complete re-implementation of the GENEPOP software for Windows and Linux. Mol. Ecol. Resour. 8, 103-106.
Saavedra C., Pena J.B., 2005, Nucleotide diversity and Pleistocene population expansion in Atlantic and Mediterranean scallops (Pecten maximus and P. jacobaeus) as revealed by the mitochondrial 16S ribosomal RNA gene. J. Exp. Mar. Biol. Ecol. 323, 138150.

Schuelke M., 2000, An economic method for the fluorecent labeling of PCR fragments. Nature Biotechnol. 18, 233-234.

Taris N., Batista F.M., Boudry P., 2007, Evidence of response to unintentional selection for faster development and inbreeding depression in Crassostrea gigas larvae. Aquaculture 272 (suppl. 1), S69-S79.

Wang J., 2009, A new method for estimating effective population sizes from a single sample of multilocus genotypes. Mol. Ecol. $18,10,2148-2164$.

Wang Y., Wang X., Wang A., Guo X., 2010, A 16-microsatellite multiplex assay for parentage assignment in the eastern oyster (Crassostrea virginica Gmelin). Aquaculture 308, S28-S33.

Waples R.S., Do C., 2010, Linkage disequilibrium estimates of contemporary N-e using highly variable genetic markers: a largely untapped resource for applied conservation and evolution Evol. Appl. 3, 3, 244-262.

Watts P.C., Mallanaphy W.J., McCarthy C., Beukers-Stewart B.D., Mosley M.W.J., Brand A.R., Saccheri I.J., 2005, Polymorphic microsatellite loci isolated from the great scallop, Pecten maximus (Bivalvia: Pectinidae). Mol. Ecol. Notes 5, 902-904.

Weir B.S., Cockerham C.C., 1984, Estimating F-statistics for the analysis of population-structure. Evolution 38, 1358-1370.

Wilding C.S., Latchford J.W., Beaumont A.R., 1998, An investigation of possible stock structure in Pecten maximus (L.) using multivariate morphometrics, allozyme electrophoresis and mitochondrial DNA polymerase chain reaction restriction fragment length polymorphism. J. Shellfish Res. 17, 131-139. 